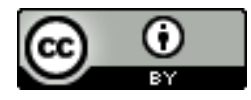

Esta obra está sob o direito de Licença Creative Commons Atribuição 4.0 Internacional.

\title{
A EDUCAÇÃO COMO PONTE DE LIGAÇÃO ENTRE O ALUNO E A SOCIEDADE: O ALUNO INSERIDO NO CONTEXTO SOCIAL ATRAVÉS DA AÇÃO ESCOLAR
}

\author{
Elisângela Oliveira Tavares ${ }^{1}$ \\ Aline Pereira do Nascimento Costa ${ }^{2}$ \\ José Petrúcio dos Santos Filho ${ }^{3}$ \\ Magna Valéria dos Santos Melo ${ }^{4}$
}

\section{RESUMO}

A escola tem um papel fundamental na construção do conhecimento do ensino aprendizagem. O professor como mediador dos conhecimentos para contribuição na formação do cidadão, contribuirá para que este aluno desenvolva o senso crítico na sua prática social. Cabe o professor coloca-se como ponte entre aluno e conhecimento. Este artigo tem por finalidade destacar a importância do papel do professor no ensino aprendizagem na construção crítica e ativa.

Palavras-chave: Professor. Conhecimentos. Prática social. Ensino. Aprendizagem.

\footnotetext{
1ely_@hotmail.com

2 aline.prof.alpi@hotmail.com

3 pettrucio@yahoo.com.br

4 mayleid@hotmail.com
} 


\section{INTRODUÇÃO}

A escola é um ambiente de aprendizagem com sua construção de conhecimento compartilhado entre aluno e professor. Pois envolve diversos aspectos entre ensinar e aprender e assim a troca de informações. A escola pela qual se busca o desenvolvimento cultural do cidadão, preparando os alunos para a vida, a educação como um instrumento de reprodução para a sociedade aquela que tem por finalidade principal a adaptação do sujeito à sociedade. A educação como instrumento de transformação da sociedade refere-se à educação crítica, áquela que tem como finalidade principal a instrumentalização do sujeito para que esses tenham uma prática social crítica e transformadora. Pois os sujeitos precisam se apropriar de conhecimentos, atitudes e valores, de forma crítica e reflexiva para que tenham condições de atuar nessa sociedade visando a sua transformação.

Nesse início de século XXI, novas perspectivas, mudanças e desafios são apresentados, pois trazem para o profissional da educação a necessidade de se colocar no mercado de trabalho com mais conhecimento e capacidade de se interagir com este mundo.

Segundo libâneo (2002), a pedagogia tem lugar diferenciado das outras ciências da educação, pois conseguem-se integrar nas diversas razão de uma aproximação global. Ela continua na conquista de desenvolvimento para o sujeito possibilitando-lhe ser capaz de construir pensamentos criativos na busca da razão social.

Tais considerações inferem que, a escola propicia a educação de todos, tem o compromisso de contribuir com aprendizagem e sucesso de cada aluno. Pressupõe-se que haja uma interação de todos em prol da educação. Diante de tal perspectiva, e sabendo envolvimento de todos, dessa forma, pode-se perceber que a escola pode ser considerada um cenário eclético, de interação de culturas diferentes entre outros fatores.

É na escola que se dá a facilitação da inserção dos indivíduos no meio social. Sendo a escola um espaço de construção do conhecimento e da reflexão da ação pedagógica. Deste modo, a escola deve ensinar a vírgula garantir uma aprendizagem significativa para os alunos, possibilitar a aprendizagem dehabilidade dos conhecimentos que são necessários para vida em sociedade, oferecendo a compreensão da realidade e favorecendo a participação dos alunos em relações sociais.

Neste sentido, é preciso que todos acreditem em cada um, olhar o aluno como sujeito e não um objeto de sua ação educativa (FREIRE, 1979 ). 


\section{A EDUCAÇÃO ATRAVÉS DA AÇÃO EDUCATIVA}

O papel do educador na área da Educação é um mediador e trabalhador social, o professor e transmissor de conhecimento ou seja é uma ponte entre o estudante e o conhecimento, dessa forma para aprendizagem dos alunos.

segundo Freire (1979), ação docente é a base de uma boa formação e contribui para uma construção de uma sociedade mais crítica, ensinar é uma responsabilidade que precisa ser trabalhada e desenvolvida.

Saviani (2003), defende uma pedagogia crítico-social dos conteúdos e a qual professor e alunos se encontram numa relação social com o objetivo de estudar os conhecimentos acumulados historicamente, a fim de construir e aprimorar novas elaborações do conhecimento, que o ponto de partida da ação pedagógica.

$\mathrm{Na}$ prática social o professor deve tratar não somente os conteúdos atuais em sala de aula, mas também, resgatar o conhecimento amplo e histórico, para que os alunos possam interpretar suas experiências e suas aprendizagens na vida social.

Kramer (1989), para que essa função se afetive na prática:

O trabalho pedagógico precisa se orientar por uma visão das crianças como seres social, indivíduos que vivem em sociedade, cidadãs. Isso exige que devemos em consideração suas diferentes características, não só em termos de histórias de vida ou de região geográfica, mas também de classe social, etnia e sexo. Reconhecer as crianças como seres sociais que são implica em não ignorar as diferenças ( Kramer, 1989, p.19).

É nesse sentido que devemos considerar as experiências sociais acumuladas de cada aluno e seu contexto social.

Segundo os parâmetros curriculares nacionais (2001), a prática social no processo de ensino e aprendizagem é um aspecto de suma importância que devem entender as relações entre desenvolvimento e aprendizagem, na relação interpessoal no processo a relação entre educação e cultura e na ação educativa na atividade construtiva do aluno no momento de escolaridade. De acordo com Saviani (2003) através da qual se detectam questões que precisam ser resolvidas na prática social e no conhecimento.

A importância social na aprendizagem da criança, o conhecimento começa a ser construído individualmente e socializado através da mediação do professor. 
crianças, mas também a sua relação com a escola e estudo, sua percepção e compreensão das matérias. A consolidação dos conhecimento depende do significado que eles carregam em relação a experiência social das crianças e jovens na família, no meio social, no trabalho (Libâneo, 1944, p.87).

Segundo os parâmetros curriculares nacionais (2001), o domínio dos conhecimentos formais para a participação crítica na sociedade, considera-se também que é indispensável uma adequação pedagógica as características de um aluno que pensa, de um professor com valor social e formativo Fontana e Cruz (1997) afirma deixar-se de esperar das crianças a postura de ouvinte valorizando-se sua ação, possibilitando que a criança em situações em que ela possa agir e ouvi-la, expressar suas elaborações possam ser princípios básicos da atuação do professor.

Rego (2001) aponta para a necessidade da criação de uma escola bem diferente da que conhecemos. Uma escola em que as pessoas possam dialogar, discutir, questionar e compartilhar saberes. Onde há espaço paratransformações, para as diferenças, para as contradições, para a colaboração mútua e para a criatividade. Uma escola em que os professores e alunos tenham autonomia, possam pensar, refletir, sobre o seu próprio processo de construção de conhecimentos e ter acesso a novas informações. Uma escola em que o conhecimento já sistematizado.

A capacidade de uma pessoa de uma comunidade de tomar decisões, construindo suas próprias regras refletindo sobre as consequências de suas ações, assumindo responsabilidades. $\mathrm{O}$ indivíduo alcance de sua autonomia, participando efetivamente de decisões que afetam sua vida social e pessoal.

Autonomia refere-se á
capacidade de posicionar-se
elaborar projetos pessoais e
participar de projetos coletivos,
organizar-se em função de
metas, participar das gestões de
ação coletivas, estabelecer
critérios e princípios éticos, etc.
Íntegra com as diferentes
dimensões da vida, o que
envolve aspectos intelectuais,
morais e sociopolíticos (PCN,
1997, p.97).

$\mathrm{Na}$ escola o desenvolvimento da autonomia está apenas nos discursos enquanto as práticas pedagógicas continuam as mesmas. Só será possível se os educadores tiverem um objetivo de vivenciarem no cotidiano de sua prática escolar.

A escola inclusiva é uma escola que esteja preparada para receber e cumprir seu papel de proporcionar um ensino de qualidade para todos, que contemple todos os educandos, onde o aluno tenha não só direito de frequentá-la, mas dentro de suas 
capacidades cultural e socialmente.

Porém o termo inclusão ainda precisa ser compreendido pois é a busca do sucesso dos alunos. A escola inclusiva é a transformação necessária para uma escola aberta para todos, aceitar as diferenças e reconhecê-las em importantíssimo para educação.

A escola inclusiva é uma escola preparada para receber o aluno, sem dar ele uma diferenciação, recebê-lo como um ser humano que tem capacidade para progredir, desde que proporcione condições para tal.

De acordo com Hantoan (2003) a abertura das escolas ás diferenças tem haver com uma revolução nos processos de ensino e de aprendizagem, pois o que se propõe é o rompimento das fronteiras entre o saber e a realidade do conhecimento que aí se formam, a transversalidade das áreas curriculares e autonomia intelectual do aluno, o autor do conhecimento com o valor que constrói individualmente e coletivamente, nas salas de aula.

Uma educação de qualidade para todos com propostas educacionais com organização curricular idealizada e executada pela comunidade escolar, de um projeto político pedagógico democrático. Baseado no meio social e cultural. A educação de qualidade para todos depende de transformação educacional, como a valorização da diversidade do desenvolvimento pessoal e social, dos currículos amplos que possibilitem as necessidades educacionais dos alunos.

De acordo com Hantoan (2003) a lei de diretrizes e bases da educação nacional é marcada pela possibilidades para realização de transformações no currículo escolar, apresenta conceitos de flexibilidade inovação orientados por concepção pedagógicas relacionadas diretamente à aprendizagem dos alunos, onde todos os processos da escola estão presentes desde princípios. Cada vez mais a participação da sociedade no planejamento educacionais.

A função social da escola definida pela constituição federal (1988), Expressa o direito de todos a educação esclarecendo que esse direito Visa o pleno desenvolvimento da pessoa para o exercício da cidadania e sua qualificação para o trabalho. Dessa forma, o essencial é assegurar uma educação de qualidade para todos.

Uma das melhores formas para possibilitar a aprendizagem na escola pode ser o trabalho em equipe. Desta forma, o docente pode-se estabelecer como o espaço onde se vive e convive, onde todos os envolvidos possam trocar ideias e experiências, trocar de papéis de quem ensina e de quem aprende.

É preciso que, pelo contrário, desde os começos do processo, vá ficando cada vez mais claro que, embora diferentes entre si, 
quem forma se forma e reforma ao formar e quem é formado forma-se e forma ao ser formado. É nesse sentido que ensinar não é transferir conhecimentos, conteúdos nem é formar é ação pela qual um sujeito criador dá forma, estilo alma ao corpo indeciso e acomodado. Não há docência sem discência, as duas se explicam e seus sujeitos, apesar das diferenças e as conotação, não se reduzem a condição de objeto, um do outro. Quem ensina, ensina alguma coisa a alguém (Freire, 1979, p.24)

Diante disso, aprendizagem possibilita um ir e vir constante, para criação de sujeitos participativos, criativos e reflexivos. $\mathrm{O}$ trabalho em equipe torna o espaço de trabalho para contribuição com a troca de experiências, de ideias e sobretudo a troca de conhecimentos aprendente um ser social.

\section{CONCLUSÃO}

Portanto, a ação pedagógica no processo de ensino e na prática social, cabe o educador, mediar conhecimentos acumulados bem como os conhecimentos atuais, pois o educando, tenha a capacidade de relacionar o conhecimento e de expressar a prática. Assim a educação deve ser sempre uma função humanitária para a construção de um cidadão crítico, e seguro do seu espaço nesta sociedade possibilitando seus direitos e com a responsabilidade de seus
Faz-se é necessário que a escola, portanto, estabeleça uma relação com seus alunos, para que estes possam apropriar-se da aprendizagem e serem sujeitos agentes de sua própria aprendizagem e do conhecimento ( Pain,1985).

O professor é mediador e facilitador da criação das condições cognitivos e afetivos que ajudaram o aluno a atribuir significados as informações recebidas das diversas fontes, com finalidades de reconstruir de forma crítica.

O pensamento de Paulo Freire (1987) coloca aqui ninguém educa ninguém, ninguém educa a si mesmo, os homens se educam entre si, a educação é uma prática social que acontece entre grupos. A participação ativa do sujeito que como produto do conhecimento, e aprendizagem.

deveres.

Uma escola de qualidade para todos, que respeita o indivíduo com suas diferenças delimitações que trata a criança como agente de sua própria aprendizagem. A qualidade na educação é como um resultado de todo um processo da aprendizagem dos sujeitos envolvidos. Essa aprendizagem resulta do desenvolvimento que deseja na construção da cidadania.

A escola precisa assumir o compromisso social de desenvolver nos 
seus alunos competências e Valores que afetivamente contribuem para a sua formação como cidadão, superando suas dificuldades e resgatando o seu desejo de aprender. Portanto, pode-se concluir que o educando deve ter uma participação ativa no processo e educativo.

Conclui-se também que a escola devem atender as crianças com afetividade,

\section{REFERÊNCIAS}

Brasil. Ministério da Educação.

Parâmetros curriculares nacionais.

Brasília: 2001.

Brasília: Mec/SEF.1997.

Fontana, Roseli; cruz, Nazaré. Trabalho pedagógico. São Paulo: Atual, 1977.

Libanês, J, C. Pedagogia e pedagogia. $5^{\circ}$ edição, São Paulo: Cortez, 2002. Freire, P.

Educação como prática. Rio de Janeiro: Paz e Terra, 1979.

Libanês, J.C. Didática. São Paulo: Cortez, 1994. interação social, e cooperação para o sucesso da aprendizagem.

Cabe ao professor ser criativo e transformador, está sempre inovando suas práticas pedagógicas de ensinoaprendizagem, podendo contribuir com ideias para que suas aulas sejam dinâmicas e criativas para a construção do conhecimento.

Mantoon, Maria Tereza. A escola. São Paulo: moderna, 2003. Brasil. Constituição Federativa do Brasil. São Paulo:1988

Pain, S. Subjetividade e objetividade com relação de desejar oconhecimento. São Paulo: 1985.

Parâmetros curriculares nacionais, ensino fundamental língua portuguesa. Rego, T.C. Cultural da educação. Petrópolis: Vozes, 2001.

Saviani, D. Escola e Democracia. 36 ed. Campinas: Autores Associados, 2003.

Kramer, S. Uma proposta curricular. São Paulo: Ático, 1989. 